\title{
Basic Education Investment Ratio Model and the Empirical Research
}

\author{
Mijiang Xue \\ Jinhe Center for Economic Research, Xi'an Jiaotong University, Xi'an 710049, China \\ E-mail:xmj.kate@stu.xjtu.edu.cn \\ Junchao Ma \\ School of Electrical Engineering, Xi'an Jiaotong University, Xi'an 710049, China \\ E-mail: mjc.890312@stu.xjtu.edu.cn
}

Xu Liu

School of Management, Xi' an Jiaotong University, Xi'an 710049, China

E-mail:1iu3347120@gmail.com

\begin{abstract}
By predicting the condition of basic education teachers in western rural area, this paper establishes a mathematical model determining western basic education investment ratio.
\end{abstract}

Keywords: Education management, Basic education, Investment ratio, Mathematical model

\section{Introduction}

Since the reform and opening up, China has made significant achievements in economic and social development. However, the economy in western area develops slowly, compared to the eastern area. Due to financial constraints and insufficient investment in education, the education, especially the basic education, has been affected negatively. In some areas, especially in rural areas and poor areas, basic education conditions are poor and teachers are in serious short, what have already become chief factors stopping the development of basic education. Although the drop-out rate of students is less than $1 \%$ because of the spread of compulsory education, we must consider the out flow of students because students and parents have lost confidence in local education (Dennis C. Mueller, 2003). The outflow of students forces schools to cut staff, resulting in loss of teachers (He, Lifang, 2006). As described in this paper, the percentage of loss of students from primary school to junior high school reaches $8.72 \%$ in average in six counties. Accordingly, the number of junior high school teachers is smaller than that of primary school. It forms a vicious circle. Also, poor treatments will directly cause the loss of teachers. Therefore, to maintain the stability of teachers and improve the quality of teachers is particularly important. In recent years, the state invests more in basic education in western counties considering the poor conditions there. The boarding school work achieves significant results. Compulsory education is free in rural areas. However, education is not done overnight. The development of teachers in western areas needs more efforts.

Schultz (Schultz,T.W., 1971) proposed the "human capital" theory: to study the driving force of economic development, it is necessary to introduce the concept of capital, both physical capital and human capital (Schultz,T.W., 1971). In this level, human resource development, human capital accumulation, and physical capital accumulation have already become the main sources of economic growth. And the two are mutually reinforcing. Therefore, to promote the development of education, the first thing is to strengthen the development of human resource, namely the cultivation of teaching staff. To cultivate a teaching staff, we should explore the potential of existing teachers and stabilize the teaching staff. Besides, we can absorb more talents to enrich the teaching staff by state policies and local governments' investments. Although the problem of teacher shortage has already been improved, the overall quality of teachers needs to be promoted.

Firstly this paper makes a brief analysis of development of western basic education based on the cultivation of teaching staff in six counties in Shaanxi province from 2004 to 2008, discussing the existing problems from the quantity and the quality of teachers, concluding that the quality of teachers has not been improved along with the increase of the quantity of teachers or even declined. Then, this paper builds a difference equation according the relations between the number of teachers, the number of students, and government investment and makes a prediction on the future five-year development of basic education in the six counties by the difference equation. The prediction shows that: with the improvement of economic conditions in western area, if the state and the local government do not invest more in the cultivation of teaching staff, the outflow of students will become more serious, and the basic education system will be in a vicious state. Finally, this paper suggests to increasing education investments in eastern area and presents a program for distributing education investments based on the principle of fairness and efficiency. 
Most papers on the construction of western teaching staff are qualitative analyses based on few data. For example, Kongzhen Li and Li Zhang, in Regional Education Development Strategy and Western Education Policy in Perspective of Experts, analyze problems in constructing western teaching staff by questionnaire. Rui Zhang, in The Public Policies in Collocating Western Education Resource in Transitional Period: Government, Market and Education, makes a qualitative analysis of state investments in perspective of the simultaneous development of economy and education. Huaxiang Gu, in A Study On the Development of Western Education and the Countermeasures, probes into the shortcomings of western education by comparing the east and the west. Hailan Pan, in An Analysis On the Development of Western Education and the Countermeasures, analyzes the necessity of state investment by discussing the impacts of the overall quality of teachers on the Great West Exploration Program. Wenli Wang, in The Problems in 1 Compulsory Education in Western Poor Rural Areas and the Sollutions, points out the distance between China's investments in western education and developed countries' investments in education, by means of comparisons, emphasizing the importance of increasing investments. Weidong Wen, in Suggestions on Funding for Western Rural Compulsory Education, focuses on local governments' unfair distribution of investments in education. Generally speaking, few articles adopt mathematical model to analyze the construction of teaching staff in western counties and seldom present ways for the distribution of state investments based on data and mathematical model. That is the value of this paper.

\section{Predict the development of basic education teachers in rural areas}

We use the students - teacher ratio to analyze the size changes of basic education teachers in western area.

Students --- teacher ratio $\left(\mathrm{st}_{\mathrm{ij}}{ }^{(\mathrm{k})}\right)=$ the number of students in school / the number of teachers in school

Here are the size changes of teaching staff in six counties in Shaanxi province from 2004 to 2008.

Insert Figure 1 Here

According to Figure 1, the development of Great West Exploration Program, China's more investments in western education, and the carry-out of teachers' promotion policy in western area have absorb lots of young teachers dedicating to western education. It basically solves the problem of more children and less teachers in western area.

The quality of teachers is mainly reflected by teachers' age structure and professional title structure. Next, we will respectively discuss teachers' age structure and professional title structure.

\subsection{Age structure}

Age structure is mainly used to value the aging issue of teacher staff. We use the proportion of key teachers, namely the proportion of teachers aging from 30 to 45 to total teachers in one year, as the index. Here we calculate the figure out the proportions of key teachers in primary schools, junior high schools, and senior high schools in different counties (take Qingjian County and Shanyang County as examples)

Insert Figure 2 Here

According to Figure 2, along with changes of time, proportions of key teachers in the two counties do not change significantly. It indicates that the aging issue of teaching staff does not arouse necessary attentions for a long time.

\subsection{Professional title structure}

China has established the lowest proportion of middle and senior teachers. Here we use the proportion of middle and senior teachers to value the professional title structure. The higher the proportion is, the higher the quality is. And the teaching quality is higher accordingly. Now we define the proportions of middle and senior teachers at different education levels.

Primary school

Proportion of middle and senior teachers $=$ number of teachers with senior titles + number of teachers with middle titles / number of teachers in primary schools

Junior and senior school

Proportion of middle and senior teachers $=$ number of teachers with senior titles + number of teachers with middle titles / number of teachers in junior high schools and senior high schools

According to files from the Education Department of Shaanxi Provincial Government, we know the requirement for teachers' professional title structure: the proportion of middle and senior teachers should be higher than $60 \%$ (Education Department of Shaanxi Provincial Government, 2004). By calculation, we get the average proportion 
of middle and senior teachers in the two counties (take Qingiian County and Shanyang County for examples) from 2004 to 2008 .

\section{Insert Figure 3 Here}

According to Figure 3, the professional title structures in the two counties do not change a lot. Similar to the age structure, it does not arouse sufficient emphasis. Although China's support policies absorb lots of talents rushing into the west, which increases the number of teachers to a great degree, the quality does not improve significantly.

Based on problem analysis and correlation analysis by SPSS, we find that the most significant factor impacting the number of teachers is the number of students. The two is a 0.994 positive correlation. Meanwhile, the number of teachers, professional title structure, and age structure are inevitably under the influences of government's investments. Surely, the number of teachers, professional title structure, and age structure can affect the number of students in adverse. Therefore, we build a differential equation on the number of students and the number of teachers.

$$
\begin{aligned}
& s_{i j}^{(k)}-s_{i(j-1)}^{(k)}=\mu_{i 1}^{(k)} \bullet\left(s t_{i(j-1)}^{(k)}-S T^{(k)}\right)+\mu_{i 2}^{(k)} \bullet\left(c o_{i(j-1)}^{(k)}-C O^{(k)}\right)+\mu_{i j}^{(k)} \bullet\left(m h_{i(j-1)}^{(k)}-M H^{(k)}\right)+r_{i}^{(k)} \\
& t_{i j}^{(k)}-t_{i(j-1)}^{(k)}=v_{1}^{(k)}\left(\alpha_{i}^{(k)} \bullet \frac{M_{i(j-1)}^{(k)}}{s_{i(j-1)}^{k}} \bullet s t_{i(j-1)}^{(k)}-M_{j}^{(k)}\right)+v_{2}^{(k)}\left(s t_{i(j-1)}^{(k)}-S T\right)+\delta_{i}^{(k)} \\
& s t_{i j}^{(k)}=\frac{s_{i j}^{(k)}}{t_{i j}^{(k)}} \\
& c o_{i j}^{(k)}-c o_{i(j-1)}^{(k)}=\left[\alpha_{i}^{(k)} \bullet \frac{M_{i(j-1)}^{(k)}}{s_{i(j-1)}^{k}} \bullet s t_{i(j-1)}^{(k)}-M_{j}^{(k)}\right] \bullet \beta_{1}^{(k)}+\left(s t_{i(j-1)}^{(k)}-S T\right) \bullet \beta_{2}^{(k)} \\
& m h_{i j}^{(k)}-m h_{i(j-1)}^{(k)}=\left[\alpha_{i}^{(k)} \bullet \frac{M_{i(j-1)}^{(k)}}{s_{i(j-1)}^{k}} \bullet s t_{i(j-1)}^{(k)}-M_{j}^{(k)}\right] \bullet \xi_{1}^{(k)}+\left(s t_{i(j-1)}^{(k)}-S T\right) \bullet \xi_{2}^{(k)}
\end{aligned}
$$

In the equation group, $s_{i j}^{(k)}$ and $t_{i j}^{(k)}$ respectively stands for the number of students and teachers in county $i$ in the year $j$ at the $k$ education level. $s t_{i j}^{(k)}, c o_{i j}^{(k)}, m h_{i j}^{(k)}$ and $M_{i j}^{(k)}$ respectively stands for the students - teacher ratio, the proportion of key teachers, the proportion of teachers with middle and senior titles, and the government investments in county $i$ in the year $j$ at the $k$ education level. $S T^{(k)}, C O^{(k)}, M H^{(k)}$ respectively stands for the widely-accepted students - teacher ratio, the proportion of key teachers, and the proportion of teachers with middle and senior titles. $M_{j}^{(k)}$ refers to the social average salary at the $k$ education level.

In the equation (1), $\mu_{1}^{(k)}, \mu_{2}^{(k)}, \mu_{3}^{(k)}$ respectively stands for students and parents' attitudes toward the students - teacher ratio, the proportion of key teachers, and proportion of teachers with middle and senior titles in county $i$ at the $k$ education level. As the three indexes above are lower than social standard, the number of students will be decreasing. $\gamma_{i}^{(k)}$ is the natural growth of students at the $k$ education level. Because the population of western area is rising, this index is positive.

In the equation (2), $\alpha_{i}^{(k)} \bullet \frac{M_{i(j-1)}^{(k)}}{s_{i(j-1)}^{k}} \bullet s t_{i(j-1)}^{(k)}$ stands for teachers' real salary in county $i$ in the year $j$ at the 
$k$ education level. $\alpha_{i}^{(k)} \bullet \frac{M_{i(j-1)}^{(k)}}{s_{i(j-1)}^{k}} \bullet s t_{i(j-1)}^{(k)}-M^{(k)}$ stands for the distance between teachers' real salary and ideal salary. $s t_{i(j-1)}^{(k)}-S T$ means the distance of teachers' real burden (how many students are directed by one teacher) and the ideal burden. $v_{1}^{(k)}$ and $v_{2}^{(k)}$ reflect teachers' attitudes toward salary and burden. $\delta_{i}^{(k)}$ is the increasing number of teachers caused by counties' favorable policies for professional promotion.

In equation (4) and (5), $\beta_{1}^{(k)}$ and $\beta_{2}^{(k)}$ respectively stands for the effects of salary and burden on teachers' age structure. $\xi_{1}^{(k)}$ and $\xi_{2}^{(k)}$ respectively stands for the effects of salary and burden on teachers' professional title structure.

According to materials (Education Department of Shaanxi Provincial Government, 2007), we find the official regulation that the proportion of teachers with middle and senior professional titles should not be smaller than $60 \%$ in senior high school, junior high school, and primary school. Considering conditions in other western areas and in the east, we define $M H^{(1)}, M H^{(2)}$ and $M H^{(3)}$ as $0.6,0.75,0.8$.

We can not get teachers' average salary by all means. Based on rough materials (Lin Yao, 2008), we suppose that teachers' average salary is equal to social average. Then, we can establish $M^{(k)}$.

Different counties have various economies, policies, geological, and human environment, parameters $\mu, v, \delta, \gamma, \beta$ and $\xi$ in above equations are different (for example, in poor areas, students and parents emphasize few on education quality, because parents are incapable of supporting children to study in better environment). Therefore, we make a cluster analysis on the construction of teaching staff in six counties by SPSS. The results are as follow.

\section{Insert Figure 4 Here}

From Figure 4, Changwu County, Ningqiang County, Shanyang County, and Shenmu County belong to the first cluster. Qingjian County and Wugong County belong to the second cluster. A further investigation finds that Qingjian County and Wugong County have the worst economy, what indicates that the economic condition in one area has the most significant impact on education. Suppose all parameters in six counties are respectively equal. Use MATLAB to get the solution. The prediction is as follow.

Insert Figure 5 Here

According to Figure 5, in future five years, if we do not adopt effective measures to strengthen the quality construction of teaching staff, the quality of teaching staff will fluctuate or decline, which will inevitably cause the outflow of local students, forming a vicious circle.

\section{Basic education investment ratio model}

According to former prediction, we know that the quality of teaching staff in western area is rising stably, but the rising rate is slow. It is predicted that people' requirements for highly-qualified basic education and constantly-improved training mechanism for teachers will make the state invest more in western rural basic education (Stephen P. Robbins, 1982). At that time, considering the different conditions in different regions, how to distribute the investment will become a focus. For example, suppose the state invests $\mathrm{S}$ ten million RMB in improving the construction of teaching staff, how to distribute the money? Based on former difference equation, following the principle of efficiency and fairness (Authur M. Okun, 1975), we present a distribution program.

The target function:

$\min =\sum_{i=1}^{6} \sum_{k=1}^{3}\left(\lambda_{1} \bullet \frac{S T^{(k)}-s t_{i j}^{(k)}}{S T^{(k)}}+\lambda_{2} \bullet \frac{C O^{(k)}-c o_{i j}^{(k)}}{C O^{(k)}}+\lambda_{3} \bullet \frac{M H^{(k)}-m h_{i j}^{(k)}}{M H^{(k)}}\right)$ 
ST.

$$
\left\{\begin{array}{l}
s_{i j}^{(k)}=\mu_{i 1}^{(k)} \bullet\left(s t_{i(j-1)}^{(k)}-S T^{(k)}\right)+\mu_{i 2}^{(k)} \bullet\left(c o_{i(j-1)}^{(k)}-C O^{(k)}\right)+\mu_{i 3}^{(k)} \bullet\left(m h_{i(j-1)}^{(k)}-M H^{(k)}\right)+r_{i}^{(k)}+s_{i(j-1)}^{(k)} \\
t_{i j}^{(k)}=v_{1}^{(k)}\left(\alpha_{i}^{(k)} \bullet \frac{M_{i(j-1)}^{(k)}}{s_{i(j-1)}^{k}} \bullet s t_{i(j-1)}^{(k)}+\frac{N_{i j}^{k}}{t_{i(j-1)}^{k}}-M_{j}^{(k)}\right)+v_{2}^{(k)}\left(s t_{i(j-1)}^{(k)}-S T\right)+\delta_{i}^{(k)}+t_{i(j-1)}^{(k)} \\
s t_{i j}^{(k)}=\frac{s_{i j}^{(k)}}{t_{i j}^{(k)}} \\
c o_{i j}^{(k)}=\left[\alpha_{i}^{(k)} \bullet \frac{M_{i(j-1)}^{(k)}}{s_{i(j-1)}^{k}} \bullet s t_{i(j-1)}^{(k)}+\frac{N_{i j}^{k}}{t_{i(j-1)}^{k}}-M_{j}^{(k)}\right] \bullet \beta_{1}^{(k)}+\left(s t_{i(j-1)}^{(k)}-S T\right) \bullet \beta_{2}^{(k)}+c o_{i(j-1)}^{(k)} \\
m h_{i j}^{(k)}=\left[\alpha_{i}^{(k)} \bullet \frac{M_{i(j-1)}^{(k)}}{s_{i(j-1)}^{k}} \bullet s t_{i(j-1)}^{(k)}+\frac{N_{i j}^{k}}{t_{i(j-1)}^{k}}-M_{j}^{(k)}\right] \bullet \xi_{1}^{(k)}+\left(s t_{i(j-1)}^{(k)}-S T\right) \bullet \xi_{2}^{(k)}+m h_{i(j-1)}^{(k)} \\
\frac{S T^{(k)}-s t_{i j}^{(k)}}{S T^{(k)}} \leq \alpha \\
\frac{C O^{(k)}-c o_{i j}^{(k)}}{C O^{(k)}} \leq \alpha \\
\frac{M H^{(k)}-m h_{i j}^{(k)}}{M H^{(k)}} \leq \alpha \\
\sum_{i=1}^{6} \sum_{k=1}^{3}\left(N_{i j}^{(k)}\right) \leq S
\end{array}\right.
$$

In these equations, $j$ stands for the distribution program at the year $j$. Because constraint conditions concern data in $j-1$ years, we can get the solution of the target function year by year.

In the above target function: $\frac{S T^{(k)}-s t_{i j}^{(k)}}{S T^{(k)}}, \frac{C O^{(k)}-c o_{i j}^{(k)}}{C O^{(k)}}, \frac{M H^{(k)}-m h_{i j}^{(k)}}{M H^{(k)}}$ respectively stands for the distance between students - teacher ratio, proportion of key teachers, proportion of teachers with middle and senior titles and social standards. Multiply with their weights $\lambda_{i}$ and get the target function. Suppose $\lambda_{1}=-0.7, \lambda_{2}=0.1$ and $\lambda_{3}=0.2$. In the constraint conditions, conditions from (7) to (11) are the deformations of difference equation. Here, $\frac{N_{i j}^{k}}{t_{i(j-1)}^{k}}$ stands for the increasing salary of teachers in county $i$ in the year $j$ at the $k$ education level due to the $\mathrm{S}$ ten million RMB investments. Conditions from (12) to (14) are fairness constraint conditions, ensuring the distance between practical values (concerning six counties' three education levels and three target values) and ideal values is less than $\alpha$. Then, it will not focus too much on certain county or education level in distribution. The condition (15) is the constraint condition for total capital.

As for the parameter $M_{j}^{(k)}$, in this equation, namely teachers' social ideal income in the year $j$ at the $k$ education level, we can predict its value by China's present GDP growth.

\section{References}

Authur M. Okun. (1975). Equality and Efficiency. Brooking Institution Press.

Dennis C. Mueller. (2003). Public Choice III. Cambridge: Cambridge University Press.

Education Department of Shaanxi Provincial Government. (2004). The Evaluation Standard for the Construction of Shaanxi County Teachers Further Study School (Trial).

Education Department of Shaanxi Provincial Government. (2007). Shaanxi Education Yearbook (2006). Xi'an: Sanqin Publishing House.

He, Lifang. (2006). A Study on the Leaving of Elementary and Middle School Teachers in Rural Area. CALIS Full-Text Database for Academic Degree Thesis. July.

Schultz,T.W. (1971). Investment in Education and of Research. Free Press. 
Stephen P. Robbins. (1982). Personnel: The Management of Human Resources (2nd ed). Engle Cliffs, NJ: Prentice-Hall.

Yao, Lin. (2008). On Strategies for the Balanced Development of Compulsory Education Faculty. CALIS Full-Text Database for Academic Degree Thesis. May.

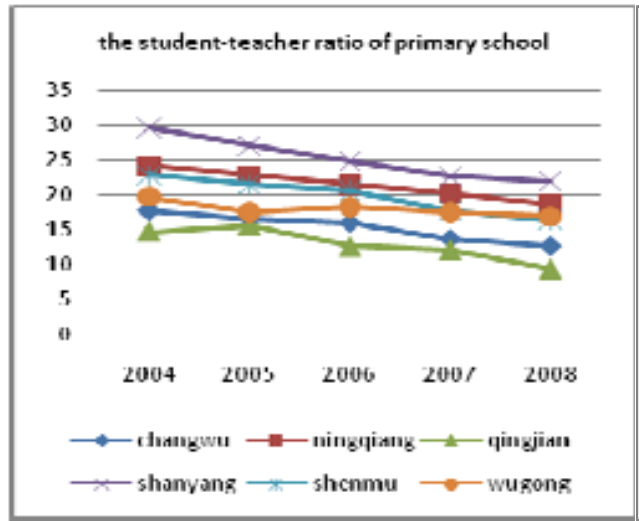

(a)

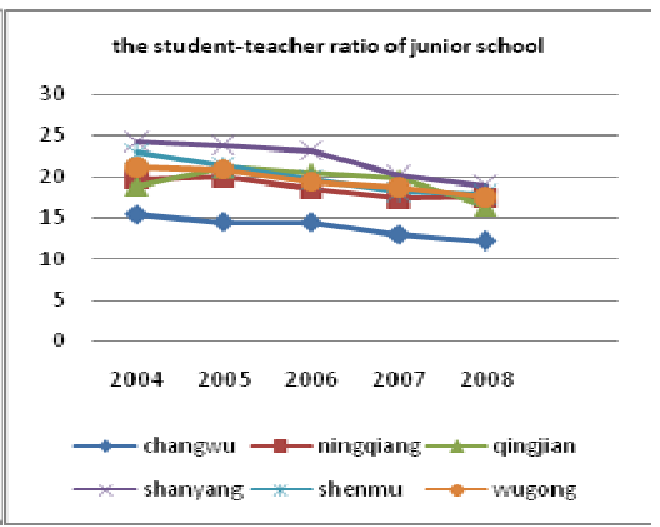

(b)

Figure 1. The Changing Trend of Students - Teacher Ratio in Primary Schools and Junior High Schools in Six Counties Year by Year

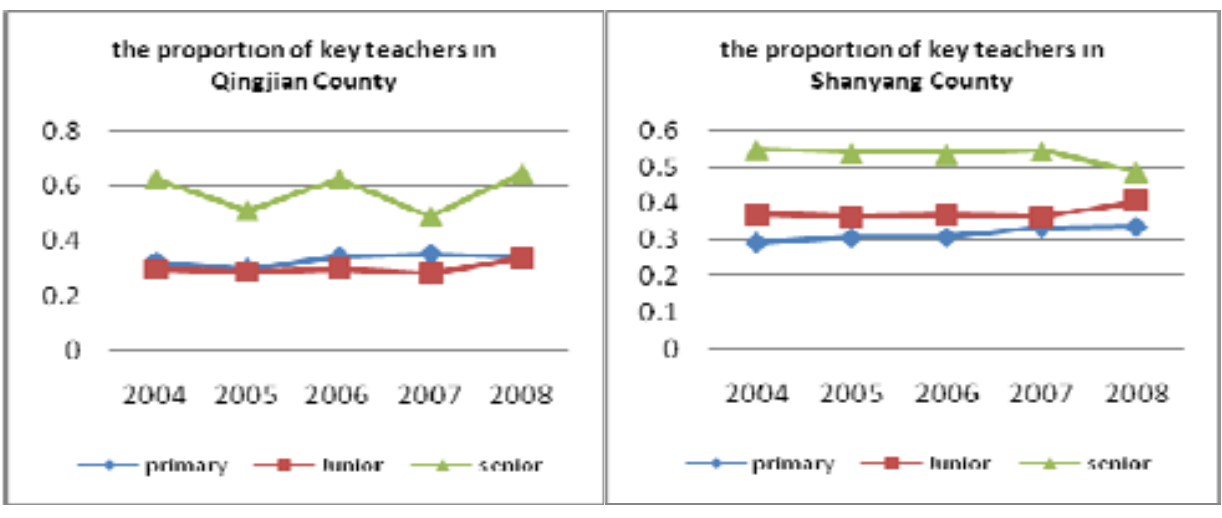

(a)

(b)

Figure 2. The Yearly Changes of Proportions of Key Teachers in Qingjian County and Shanyang County

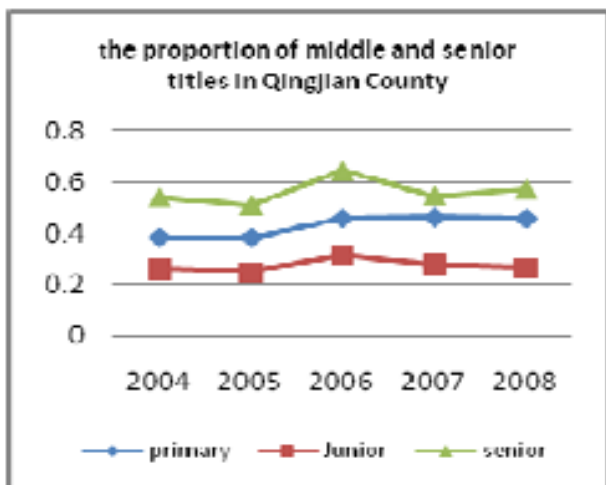

(a)

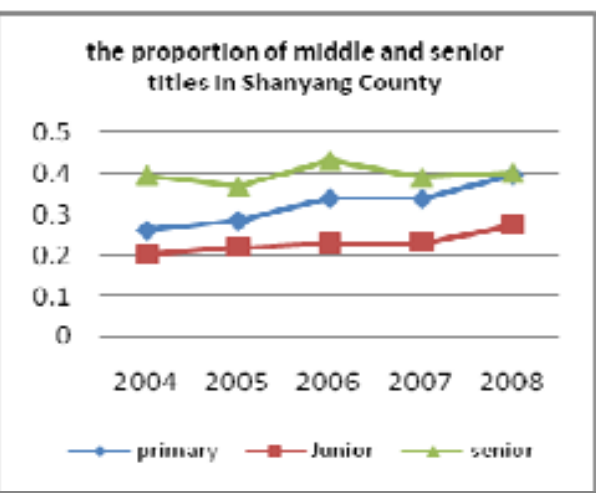

(b)

Figure 3. The Yearly Changes of Proportions of Middle and Senior Teachers in Qingjian County and Shanyang County 
Rescaled Distance Cluster Combine

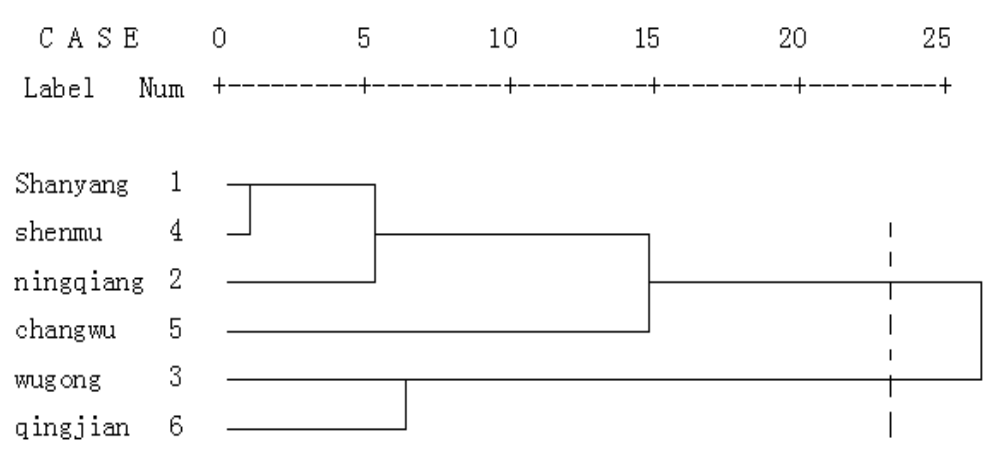

Figure 4. The Result of Cluster Analysis ------ A Tree Diagram

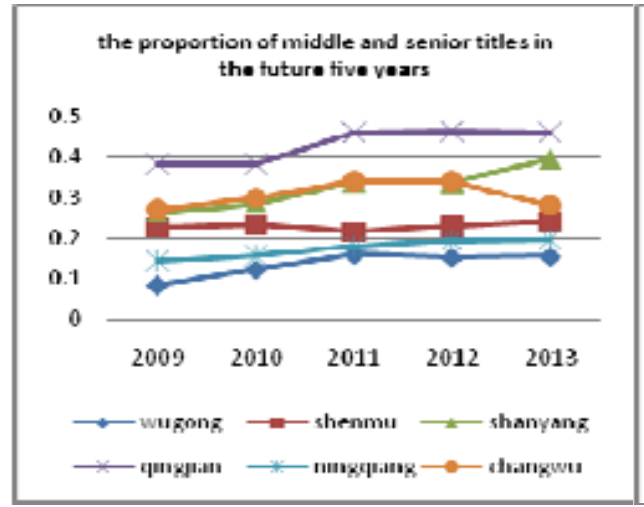

(a)

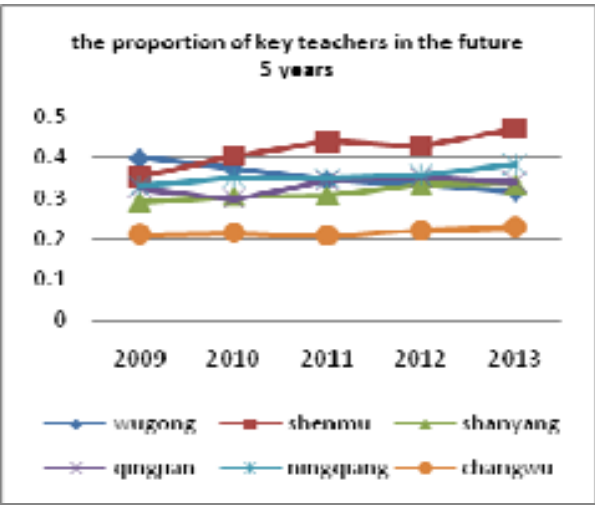

(b)

Figure 5. Prediction of the Proportion of Teachers with Middle and Senior Titles and the Proportion of Key Teachers 